\title{
Havai Rüzgâr Enerji Sistemleri için Sürekli Mıknatıslı Senkron Generator Tasarım ve Optimizasyonu
}

\author{
Esra Çelik ${ }^{*}$, Muhammet Garip \\ 1*Yıldız Teknik Üniversitesi, Makina Fakültesi, Mekatronik Bölümü, İstanbul, Türkiye, (ORCID: 0000-0002-8416-0524), f6817006 @,std.yildiz.edu.tr \\ ${ }^{2}$ Yıldız Teknik Üniversitesi, Makina Fakültesi, Mekatronik Bölümü, İstanbul, Türkiye (ORCID: 0000-0001-6315-8540), mgarip@yildiz.edu.tr
}

(İlk Geliş Tarihi 24 Aralık 2021 ve Kabul Tarihi 22 Ocak 2022)

(DOI: $10.31590 /$ ejosat.1041238)

\begin{abstract}
ATIF/REFERENCE: Çelik E., Garip M., (2022). Havai Rüzgâr Enerji Sistemleri için Sürekli Mıknatıslı Generator Tasarım ve
\end{abstract} Optimizasyonu Avrupa Bilim ve Teknoloji Dergisi. Avrupa Bilim ve Teknoloji Dergisi, (33), 154-160.

\section{$\ddot{O} \mathbf{z}$}

Havai rüzgâr enerjisi sistemleri (Airborne Wind Energy Systems), geleneksel rüzgâr türbinlerine oranla yüksek rüzgâr hızlarına ulaşabilmeleri ve daha az malzemeye gereksinim duymaları nedeniyle son yirmi yılda geleneksel rüzgar türbinlerine alternatif olarak geliştirilmiştir. Genellikle elektrik generatörünün konumuna göre tümleşik (on-board) veya yerde şeklinde sınıflandırılırlar ve her iki tipte de kule yerine kabloyu taşıyan bir halat bulunur. Bu makale, bir havai rüzgâr enerjisi sistemi için sürekli mıknatıslı radyal tip elektrik generatörünün ( $\mathrm{pmsm}$ ) elektromanyetik tasarımını ve optimizasyonunu sunmaktadır. 44kW bir sistem için ünite ve güç sayısı değiştirilerek uygun güç-ağırlık (P/W) oranını ve makinenin verimini sağlayan optimal parametreler araştırılmıştır. Analitik modeli elde edilen makinenin optimizasyonu genetik algoritma yöntemi ile Matlab yazılımı kullanılarak gerçekleştirilmiştir. Tasarım sonuçlarının doğrulanması için sonlu elemanlar analizi yöntemi Ansys-Maxwell programında uygulanmıştır.

Anahtar Kelimeler: Rüzgâr Enerjisi, Sürekli Mıknatıslı Makina, Genetik Algoritma, Optimizasyon, Sonlu Elemanlar, Airborne Wind Energy Systems

\section{Permanent Magnet Synchronous Generator Design and Optimization for Airborne Wind Energy Systems}

\begin{abstract}
Airborne wind energy systems have been developed as an alternative to conventional wind turbines in the last two decades since they can reach higher wind speeds and require less material than conventional wind turbines. They are generally classified as on-board or ground based depending on the location of the electric generator, and both types have a tether carrying the cable instead of the tower. This article presents the electromagnetic design and optimization of a permanent magnet synchronous generator (radial type) for an airborne wind power system. For a $44 \mathrm{~kW}$ system, the optimal parameters that provide the appropriate power-to-weight (P/W) ratio and the efficiency of the machine were investigated by adjusting the number of units and power. The optimization of the machine, whose analytical model was obtained, was carried out using Matlab software utilizing the genetic algorithm method. Three-dimensional finite element analysis method was used to verify the design results with the Ansys-Maxwell program.
\end{abstract}

Keywords: Wind Energy, Permanent Magnet Machine, Genetic Algorithm, Finite Elements, Airborne Wind Energy Systems.

\footnotetext{
*Sorumlu Yazar: f6817006@std.yildiz.edu.tr
} 


\section{Giriş}

Geleneksel rüzgâr türbini teknolojilerinin teknik ve ekonomik açıdan uygulanabilirlik sınırlarına ulaşması, $50-100 \mathrm{~m}$ yüksekliklerde verimli rüzgâr sahalarının halihazırda kullanıyor olması, rüzgârdan elektrik elde edilmesinde yeni tasarımları kaçınılmaz kılmıştır. Bu bağlamda alternatif bir tasarım olarak Loyd'un 1980'de ortaya koyduğu (Loyd 1980), bir hava aracının (daha çok hafif veya rijit uçurtma tipi) $300-500 \mathrm{~m}$ ve daha fazla irtifada halatla bağlı olduğu makarada dönüş yaratarak yerdeki generatörü tahrik ettiği veya hava aracının üzerinde üretim yaparak kablo ile elektriğin iletildiği kulesiz uçurtma tabanlı Havai veya Yüksek İrtifa Rüzgâr Enerji Sistemleri, 2000'lerin başında ilgi görmeye başlamış, günümüze kadar pek çok akademik çalışma grubunda farklı tasarımlar birkaç $\mathrm{kW}$ mertebelerinden $100 \mathrm{~kW}$ ve üzeri seviyelerine kadar gelişme göstermiştir (Cherubini, Papini, Vertechy, ve Fontana, 2015). Şekil 1, onboard (tümleşik) ve uçurtmalı konseptlerin temel çalışma şekilleri göstermektedir.

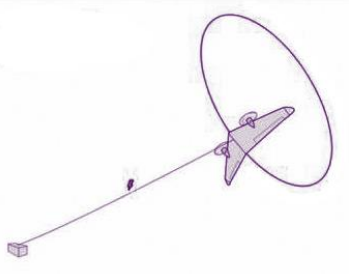

a)

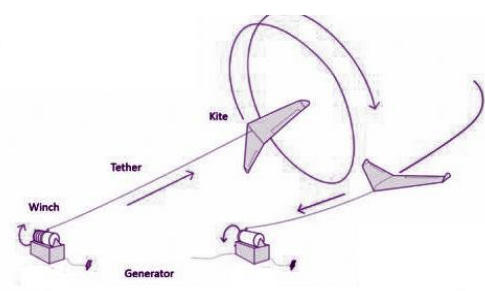

b)
Şekil 1. Havai rüzgâr enerji sistemlerini a) Tümleşik b) Yerde üretim konseptlerinin gösterimi (Airborne Wind Europe,2021) (Figure1. Concept illustration of airborne wind energy systems. a) onboard b) onground)

Havai Rüzgâr Enerji sistemleri yeni bir konsept olması sebebiyle geleneksel rüzgâr türbinlerine nazaran literatürde daha az yer bulmaktadır. Ayrıca sistemler üretim şekillerine göre farklılık göstermekte olduğundan çalışmalar pek çok ayrı kategoriye ayrılmış durumdadır. Örneğin; rijit uçak modeli veya yamaç paraşütü kullanan modeller kontrol zorluğuna rağmen yatırım maliyeti düşüklüğü sebebiyle akademik çalışmalar ve girişim şirketlerince daha çok tercih edilmektedir. Ancak otonom iniş/kalkış kabiliyetine haiz olmamaları sistem güvenirliliği açısından handikap yaratmaktadır. Örneğin firtına veya yıldırımlı havalarda sistemin güvenli yere inebilmesi önem arz etmektedir. Tümleşik (onboard) hava aracina akuple edilen tasarımda ise generatörlerin motor olarak çalıştırılması avantajı bulunmakta, bu da sistemin iniş/kalkış problemini elimine etmektedir.

Türkçe literatürde henüz yerini almamış bu sistem için doğrudan tercüme karşılığı "havada", "hava kaynaklı", "hava araçlı" tabirleri yerine yalın haliyle kavramı karşıladığını düşündüğümüz "havai" ifadesini önermekteyiz.

Literatürde benzer sistemler için generator tasarımı oldukça az olmakla birlikte yapılan çalışmada (Subotic, Gammeter, Tüysüz ve Kolar, 2015) tarafından yapılan çalışmada $1 \mathrm{~km}$ yükseklikte $100 \mathrm{~kW}$ güç üreten hava araçlı rüzgâr enerji sistemi için eksenel akılı sürekli mıknatıslı makinenin elektromanyetik, termal ve yapısal analitik modelleriyle optimizasyonu gerçekleştirilmiştir. Optimal sonuç arama algoritması olarak herhangi bir amaç fonksiyonuna bağlı kalmaksızın tüm çalışma uzayını tarayan doğrudan ızgara arama algoritması kullanılmıştır. Çalışma sonucunda kütlesel güç yoğunluğu $6.4 \mathrm{~kW} / \mathrm{kg}$, nominal hız 3200 rpm ve verim \%95 olarak bulunmuştur. Bir diğer çalışmada ise (Gammeter, Drapela, Tüysüz ve Kolar, 2015) ise, $1 \mathrm{~km}$ yükseklikte $100 \mathrm{~kW}$ hava araçlı rüzgâr türbini için verim kısıtı altında ağırlık optimizasyonu yaptıkları çalışmada radyal ve eksenel akılı makine topolojilerini, elektromanyetik ve termal modellerini kullanmışlardır. Optimizasyon metodu için maliyet fonksiyonu olmaksızın doğrudan arama metodu uygulanmıştır. Çeşitli radyal ve eksenel akılı toplojiler arasında dahili rotorlu Hallbach radyal akılı makinenin en iyi sonuçları verdiği tespit edilmiştir. Güç ağırlık oranı $6.2 \mathrm{~kW} / \mathrm{kg}$ ve $\% 96$ verim elde edildiği raporlanmıştır.

Bu çalışmada $44 \mathrm{~kW}$ bir havai rüzgâr enerji sistemi için radyal tipli sürekli mıknatıslı generatörün farklı ünite ve güç sayılarında ağırlık/kütle $(\mathrm{P} / \mathrm{W})$ oranı ve verim değerleri elde edilmiştir. Makinanın analitik modeli çıkarılarak, belirlenen değişkenlere göre Matlab Genetik Algoritma çözücüsü ile optimize edilmiştir. Elde edilen tasarımlar Ansys-Maxwell sonlu elemanlar programı ile analiz edilmiştir.

\section{Materyal ve Metot}

\subsection{Tasarım Gereksinimlerinin Belirlenmesi}

Havai rüzgâr enerji sistemleri, geleneksel rüzgâr türbinlerine kıyasla iki önemli avantaja sahiptir. Bunlardan ilki karasal türbinlerin erişemeyeceği yüksekliklere ulaşmak; diğeri ise hava aracının rüzgâra karşı gerçekleştirdiği hareket sonucu türbinlerin bağıl hıza maruz kalmasıdır. Yüksek rüzgâr hızı sayesinde türbin rotorları eşdeğer karasal türbin rotorlara oranla belirgin oranda daha küçük olmaktadır. İdeal rüzgâr enerjisi formülü Denklem 1 ile ifade edilmektedir (Aull, Stough ve Cohen, 2020).

$$
P_{\text {max }} \leq \frac{8}{27} \rho A_{\text {rot }} V_{a}^{3}
$$

Burada $P_{\text {max }}$, elde edilebilecek maksimum güç $(\mathrm{kW}), \rho$ hava yoğunluğu $(\mathrm{kg} / \mathrm{m} 3), A_{\text {rot }}$ türbin rotorlarının toplam alanı $\left(\mathrm{m}^{2}\right)$ ve $V_{a}$ bağ 1 l hızı $(\mathrm{m} / \mathrm{s})$ ifade eder. Denklem 2 'de ise türbinin güç katsayısı ile üretilebilecek mekanik gücün ifadesi verilmiştir. Denklemde $C_{p}$ ve $\rho$ sırasıyla güç katsayını ve hava yoğunluğuna karşılık gelmektedir.

$$
P_{m}=\frac{1}{2} C_{p} \rho A_{\text {rot }} V_{a}^{3}
$$

Türbin güç katsayısı $\left(C_{p}\right)$ katsayının 2 kanat kullanması kabulü ile 0,2 olarak uygulanmıştır (Rancourt, Bolduc-Teasdale, Bouchard, Anderson ve Mavris, 2016).

$$
\begin{aligned}
& w_{m}=\frac{\lambda u_{w}}{R} \\
& \lambda_{o p t}=\frac{4 \times \pi}{2}
\end{aligned}
$$

Denklem 3, $w_{m}$ (rad/s) olarak açısal hızın ifadesidir. Açısal hız kanat-uç hız oranı (TSR- tip speed ratio) ve türbinin maruz kaldığ 1 rüzgâr hızına $(\mathrm{m} / \mathrm{s})$ bağlıdır. Denklem 4 'te ise optimum kanat uç hız oranını kanat sayısına bağlı olarak elde edilişi gösterilmektedir (Carlos, Bulmaro, Honorato, ve Amparo, 2010).

Türbin verimi 0.7 kabul edildiğinde rüzgârdan alınacak mekanik güç $62,857 \mathrm{~kW}$ olarak kabul edilebilir. Bu kapasiteye göre; $V_{a}$ 
maksimum $40 \mathrm{~m} / \mathrm{s}$ (Aull, Stough ve Cohen, 2020), $C_{p}$ 0,2 ve $\rho$ hava yoğunluğu $1,225 \mathrm{~kg} / \mathrm{m}^{3}$ olmak üzere ünite sayısına göre kapasite, kanat çapı ve dönüş hızları Tablo 1'de verilmiştir.
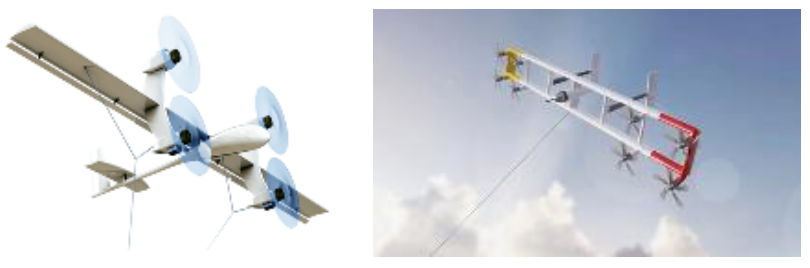

Şekil 2.Farkl ünite sayıları ile geliştirilen sistem örnekleri (Windlift,2021), (Kitekraft,2021) (Figure2. Examples of systems developed with different unit numbers)

\begin{tabular}{|c|c|c|c|c|}
\hline $\begin{array}{l}\text { Ünite } \\
\text { Sayıs1 }\end{array}$ & Güç & Kanat Çap1 & Açısal Hız & $\begin{array}{c}\text { Dönüş } \\
\text { Hizı }\end{array}$ \\
\hline & $(\mathrm{kW})$ & (m) & $(\mathrm{rad} / \mathrm{s})$ & (rpm) \\
\hline 2 & 22 & 1.146 & 217,11 & $\begin{array}{c}2073 \sim \\
2200\end{array}$ \\
\hline 4 & 11 & 0.81 & 307 & $\begin{array}{c}2931 \sim \\
3000\end{array}$ \\
\hline 8 & 5.5 & 0.57 & 436.3 & $\begin{array}{c}4166 \sim \\
4200\end{array}$ \\
\hline
\end{tabular}

Tablo 1.Farklı ünite sayısı ve güçler için hesaplanan dönüs hızları (Table 1. Calculated rotational speeds for different number of units and Powers)

\subsection{Generatörün Analitik Modelinin Elde Edilmesi}

$\mathrm{Bu}$ bölümde makine tasarımı için gerekli denklem seti elde edilmiştir. Kalıcı mıknatıslı generatörün hava aralığında hesaplanan elektromanyetik güç denklemi Denklem 5 ile ifade edilmektedir. Denklemde, $E_{1}$ yüksüz ters elektro-motor kuvvet (V), $I_{1}$ etkin faz akımı (A) ve $P_{e m}$ elektromanyetik güç (W) değerlerini göstermektedir.

$$
P_{e m}=3 E_{1} I_{1}
$$

$N_{a}$, (faz başına) sarım sayısı, $K_{d p 1}$ sarım faktörü, $B_{\delta 1}$ hava aralığ 1 ak1 yoğunluğunun birinci harmoniği-temel bileşeni (T), L makinenin eksenel uzunluğu $(\mathrm{m})$ ve $\mathrm{n}$ rpm cinsinden optimal hız olmak üzere $E_{1}$ back-EMF Denklem 6 ile elde edilir.

$$
E_{1}=\frac{\pi}{30} N_{a} K_{d p 1} B_{\delta 1} D_{s i} L n
$$

Makinenin boyutlarını azaltma ve güç yoğunluğunu artırma olanağından ötürü, $t$ makine periyodu ve Ns oluk sayısı olmak üzere $2 \mathrm{p}=\mathrm{Ns} \pm 2 \mathrm{t}$ oluk/kutup kombinasyonu seçilmiştir (Seo et al., 2013). Oluk/kutup 24/20 veya 48/40 kombinasyonları için sarım faktörü $K_{d p 1}$ tek katmanlı sarım şekli için 0.966 ve aynı kombinasyonda çift katmanlı sargıda 0.933 olarak belirlenmiştir (Emetor, 2021).

$B_{\delta}$, hava aralığı akı yoğunluğu radyal bileşeninin analitik olarak elde edilmesi için, yüzey mıknatıslı oluksuz sürekli mıknatıslı makine için türetilen Denklem 7 kullanılmıştır (Zhu, Howe, Bolte, ve Ackermann,1993). Bu denklemde $B_{\delta i}, B_{r}$ ve $\alpha_{p}$ sirasıyla hava aralığı ak1 yoğunluğunun i. harmoniği, kalıcı mıknatısın remenans değeri, kutup-yay kutup-adım oranı değerini temsil eder.

$$
\begin{aligned}
& B_{\delta}(\theta) \\
& =\sum_{i=1,3,5, \cdots}^{\infty} B_{\delta i}(\theta)=\sum_{i=1,3,5, \cdots}^{\infty} \frac{4}{i \pi} \frac{B_{r}}{\mu_{r}} \sin \frac{i \pi \alpha_{p}}{2} \frac{i p}{(i p)^{2}-1} \\
& \cdot\left\{\frac{(i p-1)+2\left(\frac{D_{r}}{D_{m}}\right)^{i p+1}-(i p+1)\left(\frac{D_{r}}{D_{m}}\right)^{2 i p}}{\frac{\mu_{r}+1}{\mu_{r}}\left[1-\left(\frac{D_{r}}{D_{s i}}\right)^{2 i p}\right]-\frac{\mu_{r}-1}{\mu_{r}}\left[\left(\frac{D_{m}}{D_{s i}}\right)^{2 i p}-\left(\frac{D_{r}}{D_{m}}\right)^{2 i p}\right]}\right.
\end{aligned}
$$

Makinenin ikincil parametreleri olan $b_{s y}$ stator boyunduruğu kalınlığ $1, b_{r y}$ rotor çekirdek kalınlığı ve $b_{s t}$ stator diş genişliği kalınlığı hava aralığı ak1 yoğunluğuna bağlı olarak Denklem 8'de gösterildiği gibi hesaplanmaktadır (Zhang, L1, Zhang, 2020). Denklemde $D_{\delta}$ hava aralığı ortalama çevresel uzunluğu, $D_{m}$ rotor dış çapını (mıknatıs dahil), $D_{r}$ rotor çekirdeğinin dış çapını, $B_{s m}$ stator maksimum ak1 yoğunluğunu, $B_{r m}$ rotor maksimum ak1 yoğunluğu, $\gamma_{s}$ oluk açısı, $\tau$ kutup açısını, p kutup çifti sayısını ve q kutup başına oluk sayısını ifade etmektedir.

$$
\begin{aligned}
& b_{s t}=\frac{D_{\delta}}{2 B_{s m}} \int_{-\frac{\gamma s}{2}}^{\frac{\gamma_{s}}{2}} B_{\delta}(\theta) d \theta \\
& \left\{\begin{array}{l}
b_{s y}=\frac{D_{\delta}}{4 B_{s m}} \int_{-\frac{\pi s}{2}}^{\frac{\gamma_{s}}{2}} B_{\delta}(\theta) d \theta q \leq 1.5 \\
b_{s y}=\frac{D_{\delta}}{4 B_{s m}} \int_{-\frac{\tau}{2}}^{\frac{\tau}{2}} B_{\delta}(\theta) d \theta q>1.5
\end{array}\right. \\
& b_{r y}=\frac{D_{\delta}}{4 B_{r m}} \int_{-\frac{\tau}{2}}^{\frac{\tau}{2}} B_{\delta}(\theta) d \theta
\end{aligned}
$$

Elde edilen kesitlere göre $A_{s}$ oluk alanı hesabı makina geometrisinde elde edilmektedir.

$$
\begin{aligned}
A_{s}=\frac{\pi}{4 N_{s}}\left(D_{s o}^{2}-D_{s i}^{2}\right)-\frac{\pi}{4 N_{s}} & {\left[D_{s o}^{2}-\left(D_{s o}-2 b_{s y}\right)^{2}\right] } \\
& -b_{s t}\left(D_{s o}-2 b_{s y}-D_{s i}\right)
\end{aligned}
$$

Makine verimliliğinde büyük önem taşıyan ve iletkenin akım taşıma kapasitesi ile sınırlanan $\mathrm{J}$ akım yoğunluğu $\left(\mathrm{A} / \mathrm{mm}^{2}\right)$ değeri Denklem 10 ile ifade edilir. $K_{C u}$ oluk alanın doluluk oranını $N_{S}$ ise toplam oluk sayısını gösterir.

$$
J_{c u}=\frac{6 N_{a} I_{1}}{K_{C u} N_{s} A_{s}}
$$

Toplam sarg1 kütlesini tespit edebilmek için sarg1 sonralarının doğru şekilde hesaplanması önem arzetmektedir. Denklem 11'de $y_{q}$ bobin adımını temsil etmektedir oluk ve kutup sayısı oranının en yakın tam sayı değeri olarak hesaplanır. Stator dişinin yarı yüksekliğinde ölçülen oluk aralığı $p_{s}^{\prime}$, Denklem 12'de gösterildiği şekilde hesaplanmaktadır. Burada $h_{t}$ oluk yüksekliği olup tasarım boyunca Denklem 8 ile üretilen $b_{s t}$ stator diş kalınlığının iki katı kabul edilmiştir. $L_{e w}$ sargı sonu uzunluğu nihai olarak Denklem 13 ile elde edilir ve sargı kütlesinin hesabında eksenel uzunluğa ilave edilerek kullanılır (Bianchi, Bolognani, ve Frare, 2006).

$$
\begin{gathered}
y_{q}=\operatorname{Int}\left(\frac{N_{s}}{2 P}\right) \\
p_{s}^{\prime}=\pi\left(D_{s i}+h_{t}\right) / N_{s} \\
L_{e w}=\frac{\pi}{2} \frac{p_{s}^{\prime}+b_{s t}}{2}
\end{gathered}
$$


Makinenin aktif malzeme kütlesi Denklem 14 ile gösterilmiştir. Makine geometrisinden yararlanılarak elde edilen kütle değerleri Denklem 15-18 takımıyla bulunur. Sirasıyla $m_{s c}$ stator, $m_{r y}$ rotor, $m_{m a g}$ mıknatıslar, $m_{C u}$ bakır sargıların ağırlıklarının karşılığıdır.

$$
\begin{gathered}
m_{\text {toplam }}=m_{s c}+m_{r y}+m_{m a g}+m_{C u} \\
m_{s c}=\rho_{s c} L\left[\frac{\pi}{4}\left(D_{s o}^{2}-D_{s i}^{2}\right)-N_{s} A_{s}\right] \\
m_{r y}=\frac{\pi}{4} \rho_{r y} L\left[D_{r}^{2}-\left(D_{r}-2 b_{r y}\right)^{2}\right] \\
m_{C u}=\rho_{C u} A_{s} K_{C u} N_{s}\left(L+l_{e w}\right) \\
m_{m a g}=\frac{\pi}{4} \alpha_{p} \rho_{m a g} L\left(D_{m}^{2}-D_{r}^{2}\right)
\end{gathered}
$$

Generatörün verimi bakır ve demir kayıpları ile hesaplanmıştır. $P_{c u}$ bakır kaybı Denklem 19'da gösterildiği şekilde $I_{p h}$ faz akımı ve $R_{p h}$ bir faz direnci ile elde edilebildiği gibi $\mathrm{J}_{\mathrm{cu}}$ akım yoğunluğu ve sargıların hacmine bağlı olarak ifade edilebilir (Adhikari, Panda, 2015). Analitik modelde akım yoğunluğu üzerinden bakır kaybı elde edilmiştir. Bakırın iletkenlik değeri $\sigma_{c u} \quad 58,7 \mathrm{M}$ Siemens/m alınmıştır. Denklem 20'de ise demir kayıplarının bileşenleri gösterilmiştir. Histerezis ve nüve kayıp katsayıları; $K_{h}$ histerezis kayıp katsayısı, $K_{c}$ girdap akımları kayıp katsayıs1, $K_{e}$ ek girdap kayıp katsayısı olmak üzere statorda kullanılan M19 elektriksel çelik malzemesi için sirasıyla 164,2, 2,5, 1,79322 kabul edilmiştir (Tarımer, Arslan ve Güven, 2012). Ayrıca $B_{\max }$, statordaki maksimum akı yoğunluğunu, $\mathrm{f} \mathrm{Hz}$ cinsinden makina frekansını ve $V_{s c}$ stator demir hacimini $\mathrm{m}^{3}$ olmak üzere temsil etmektedir.

$$
\begin{gathered}
P_{c u}=3 I_{p h}^{2} R_{p h}=J_{c u}^{2} V_{c u} / \sigma_{c u} \\
P_{\text {ir }}=\left(K_{h} B_{\text {max }}^{2} \mathrm{f}+K_{c}\left(B_{\text {max }} f\right)^{2}+K_{e} B_{\max }^{2} f^{2}\right) V_{s c} \\
P_{\text {kayıp }}=P_{c u}+P_{i r}
\end{gathered}
$$

Giriş gücü kayıpların Pem güce ilave edilmesi ile Denklem 22'de gösterildiği gibi bulunur ve Generator verimi $\eta_{g}$, hesabı giriş gücün çıkışa oranıyla Denklem 23'teki gibi hesaplanır. Nihai güç/ağırlık oranı $(\mathrm{P} / \mathrm{W})$ ise Denklem 24'te gösterilmiştir.

$$
\begin{aligned}
& P_{\text {giriş }}=P_{\text {em }}+P_{\text {kayıp }} \\
& \eta_{g}=\left(P_{\text {giriş }} / \text { Pem }\right) \times 100 \\
& P / W=\frac{\text { Pem }}{m_{\text {toplam }}}
\end{aligned}
$$

Analitik modelde seçilen malzemelere ait karakteristik bilgiler Tablo 2'de yer almaktadır.

\begin{tabular}{c|cc} 
Kısım & Malzeme & Kütle Yoğunluğu $\left(\mathrm{kg} / \mathrm{m}^{3}\right)$ \\
\hline Stator & M19-29 & 7650 \\
Rotor & M19-29 & 7650 \\
Miknatıs & NdFe35 & 7400 \\
Sarg1 & Bakır & 8900
\end{tabular}

Tablo 2. Seçilen malzemeler ve özellikleri (Table 2. Selected materials and their properties)

\subsection{Optimizasyon}

Üretilen analitik model Matlab yazılımında Genetik Algoritma Çok Amaçlı Optimizasyon çözücüsü ile optimize edilmiştir. Tasarım kriterleri Tablo 3 'te gösterildiği gibidir. Modelde $R_{s i}$ stator iç yarıçapı, $g$ hava aralığı yüksekliği, $h_{m}$ mıknatıs kalınlığ1 ve $L$ makinanın eksenel uzunluğu değişken olarak belirlenmiştir. Denklem seti toplam kütleyi minimize ederken verimliliği maksimize edecek şekilde çok amaçlı bir optimizasyon problemi elde edilmiştir.

\begin{tabular}{rrrr}
\hline \multicolumn{4}{c}{ Generatör Tasarım Parametreleri } \\
\hline Ünite Sayısı & Güç (kW) & Gerilim (V) & Devir Sayısı (rpm) \\
\hline 2 & 22 & 300 & 2200 \\
\hline 4 & 11 & 300 & 3000 \\
\hline 8 & 5.5 & 300 & 4200 \\
\hline
\end{tabular}

Tablo 3. Tasartm kriterleri (Table 3. Design criteria)

Ayrıca optimizasyonda akım yoğunluğu $J_{c u}$, tasarımın doğal soğutmalı olması sebebiyle kisit olarak uygulanmıştır. Değişkenlere ve kısıta dair sınır değeleri Tablo 4'te gösterilmiştir.

\begin{tabular}{cccc}
\hline Değişken & Alt sınır & Üst Sınır & Birim \\
\hline $\boldsymbol{R}_{\boldsymbol{s i}}$ & 10 & 300 & $\mathrm{~mm}$ \\
\hline $\boldsymbol{h}_{\boldsymbol{m}}$ & 2 & 8 & $\mathrm{~mm}$ \\
\hline $\boldsymbol{g}$ & 0,1 & 1,5 & $\mathrm{~mm}$ \\
\hline $\boldsymbol{L}$ & 10 & 60 & $\mathrm{~mm}$ \\
\hline Kisıt & & & \\
\hline $\boldsymbol{J}_{\boldsymbol{c u}}$ & 3 & 5.5 & $\mathrm{~A} / \mathrm{mm}^{2}$ \\
\hline
\end{tabular}

Tablo 4. Optimizasyon değişken ve klsıt sinırları (Table 4. Optimization variable and constraint limits)

Çok amaçlı optimizisyon ile Şekil 3'te yer alan pareto-front çözüm kümeleri elde edilmiştir. Amaç fonksiyonunda verim (1n) ile ifade edilerek sonuç minimize edilerek verim (n) değerinin maksimize edilmesi sağlanmıştır. Her üç generator için de güçağırlık oranını yaklaşık $1 \mathrm{~kW} / \mathrm{kg}$ ve verimin \%94-95 civarında olduğu gözlemlenmiştir.

Optimum değişken değerlerinin analitik denklem setinde uygulanması ile belirlenen generatör kesitleri Tablo 5'te gösterilmiştir. Analitik çözüm sonucu oluşan kütle ve verim değerleri Ansys-Maxwell 3D programı ile analiz edilerek sonuçlar çalışmanın bulgular bölümünde tartışılmıştır.

\section{Pareto-Front Çözümleri}

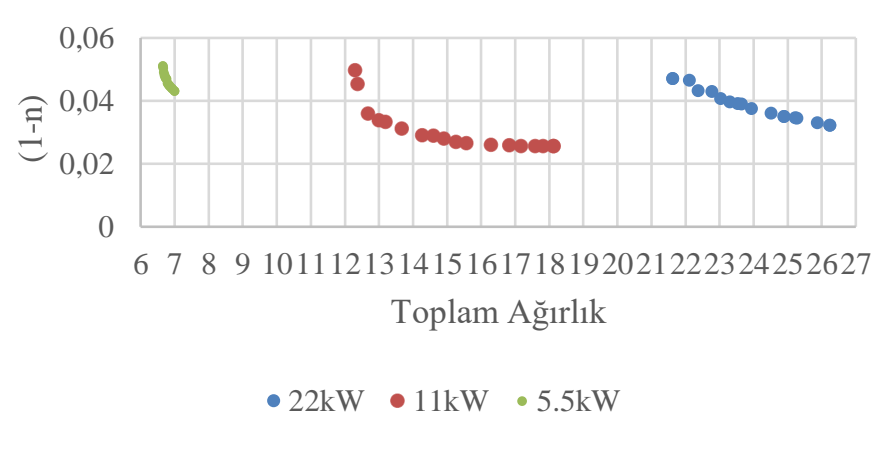

Şekil 3. Pareto-Front çözüm sonuçları (Figure 3. Pareto-Front solution results) 


\subsection{Elektromanyetik Sonlu Elemanlar Analizi}

Elektrik makinalarında kullanılan malzemelerin doğrusal olmayan yapısal özellikleri sebebiyle analitik işlemlerle bulunan tasarım kesitleri sonlu elemanlar analizi yardımıyla gerçeğe en yakın şekilde modellenerek makine performansı analiz edilir. $\mathrm{Bu}$ çalışmada da optimizasyonun analitik model üzerinden ürettiği kesitlerle oluşan üç farklı güçteki generatör Ansys-Maxwell 3D yazılımı ile analiz edilmiştir. Şekil 4 sonlu elemanlar analizi ile elde edilen akı ve akım yoğunluğu sonuçları göstermektedir.

Şekil 4 incelendiğinde 22 ve $11 \mathrm{~kW}$ güçlerdeki generatörlerde stator dişleri haricinde optimizasyon ile belirlenen stator ve rotor boyunduruklarında doyum olmadığı görülmektedir. Bununla birlikte $5.5 \mathrm{~kW}$ 'lık generatörde stator dişlerinin yanısıra rotor boyunduruğunda dahi doyum gözlemlenmiştir. Analitik optimizasyon modelinin 22 ve $11 \mathrm{~kW}$ ölçekli generatörlerde daha doğru sonuç verdiği sonucuna varılmıştır. Aynı şekilde tasarlanan generatorlerin verim tayini için program ile kayıplar tespit edilmiştir. Şekil 5 demir kayıplarını Şekil 6 ise bakır kayıplarını göstermektedir.

Generatörlerin dönüş hızlarının yüksek olması demir kayıplarını baskın hale getirmiştir. Kayıpların büyük çoğunluğunu her üç generatörde de demir kayıpları oluşturmaktadır. Ancak analitik çözümler, sonlu elemanlar analizi sonucuna göre büyük oranda sapmaktadır. Bu durum kayıp modelinin daha detaylı irdelenmesi ve modellenmesinin gerektiğini göstermektedir.

\begin{tabular}{|c|c|c|c|c|c|c|c|c|c|c|c|}
\hline Simge & Kesit & Units & $22 \mathrm{~kW}$ & $11 \mathrm{~kW}$ & $5 \mathrm{~kW}$ & Simge & Kesit & Units & $22 \mathrm{~kW}$ & $11 \mathrm{~kW}$ & $5 \mathrm{~kW}$ \\
\hline $\mathrm{D}_{\mathrm{so}}$ & Stator diş çapı & $\mathrm{mm}$ & 525,4 & 326,3 & 207,8 & Ns & Oluk sayısı & $\mathrm{mm}$ & 48 & 24 & 24 \\
\hline $\mathrm{D}_{\mathrm{si}}$ & Stator iç çap1 & $\mathrm{mm}$ & 416,7 & 216,9 & 134,9 & $\mathrm{P}$ & Kutup sayısı & $\mathrm{mm}$ & 20 & 20 & 20 \\
\hline $\mathrm{D}_{\mathrm{m}}$ & Rotor dış çapı & $\mathrm{mm}$ & 414,7 & 215,6 & 134,1 & $\mathrm{~b}_{\mathrm{st}}$ & Stator diş kalınlığ & $\mathrm{mm}$ & 15,5 & 15,6 & 12,9 \\
\hline $\mathrm{D}_{\mathrm{ri}}$ & Rotor iç çap1 & $\mathrm{mm}$ & 396,5 & 195,9 & 117,9 & $b_{\text {ry }}$ & $\begin{array}{l}\text { Rotor boyunduruk } \\
\text { kalınlığ } 1\end{array}$ & $\mathrm{~mm}$ & 6,7 & 6,8 & 5,6 \\
\hline $\mathrm{L}$ & Eksenel uzunluk & $\mathrm{mm}$ & 34,1 & 32,9 & 38,8 & $b_{\text {sy }}$ & $\begin{array}{l}\text { Stator boyunduruk } \\
\text { kalınlığ } 1\end{array}$ & $\mathrm{~mm}$ & 7,8 & 7,8 & 6,4 \\
\hline $\mathrm{h}_{\mathrm{m}}$ & $\begin{array}{c}\text { Miknatıs } \\
\text { yüksekliği }\end{array}$ & $\mathrm{mm}$ & 2,5 & 3 & 3,6 & $h_{t}$ & Oluk yüksekliği & $\mathrm{mm}$ & 38,8 & 46,9 & 26 \\
\hline $\mathrm{g}$ & $\begin{array}{l}\text { Hava aralığ } 1 \\
\text { yüksekliği }\end{array}$ & $\mathrm{mm}$ & 0,98 & 0,65 & 1,1894 & $\mathrm{w}_{\mathrm{t}}$ & Oluk genişliği & $\mathrm{mm}$ & 14,8 & 25,8 & 15,7 \\
\hline
\end{tabular}

Tablo 5. Optimizasyon sonucu elde edilen kesit değerleri (Table 5. Cross-section values obtained as a result of optimization)

$22 \mathrm{~kW}$
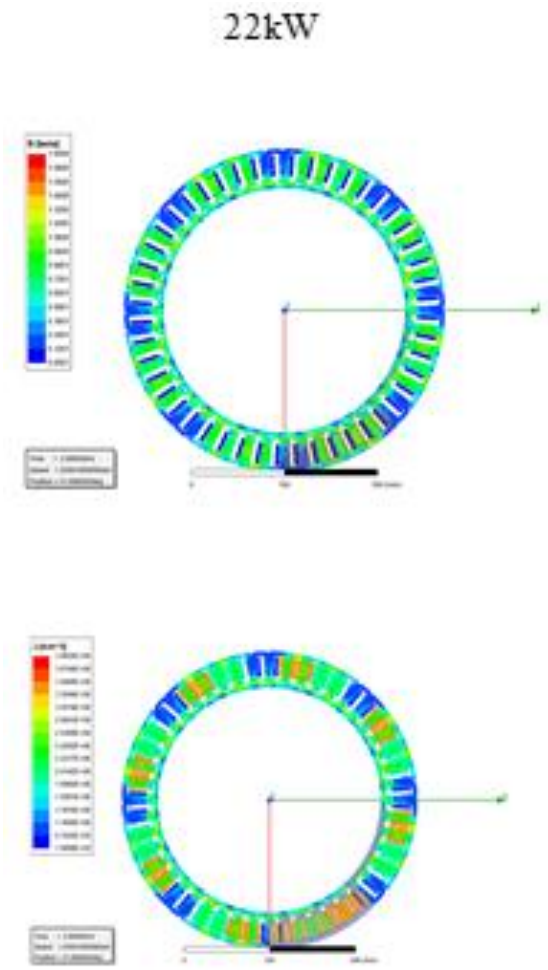

$11 \mathrm{~kW}$

B Ak1 yoğunluğu

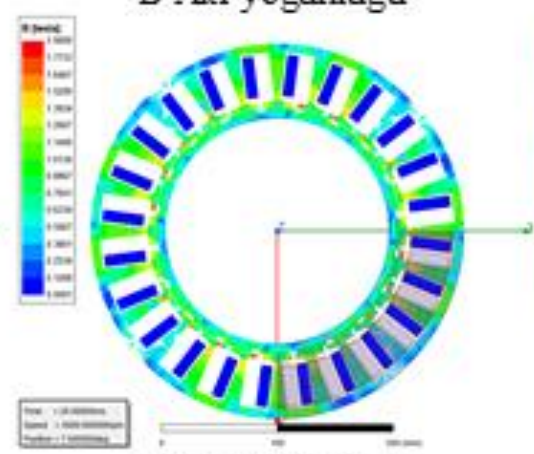

J Akım Y oğunluğu

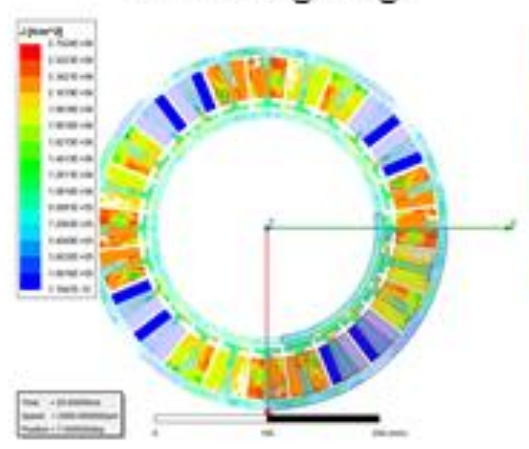

$5.5 \mathrm{~kW}$
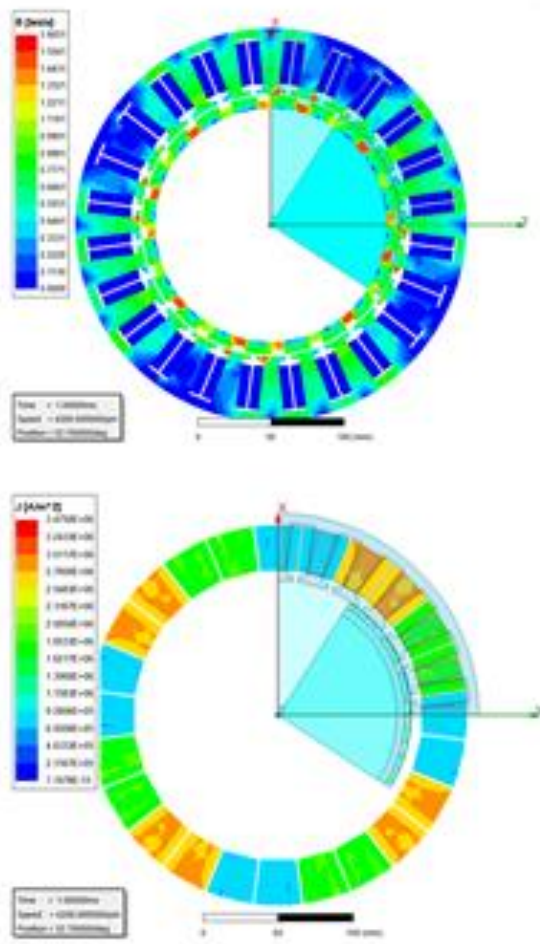

Şekil 4. Farklı güçlerde tasarlanan generatörlerin SEA sonuçları (Figure 4. FEA results of generators designed at different powers) 


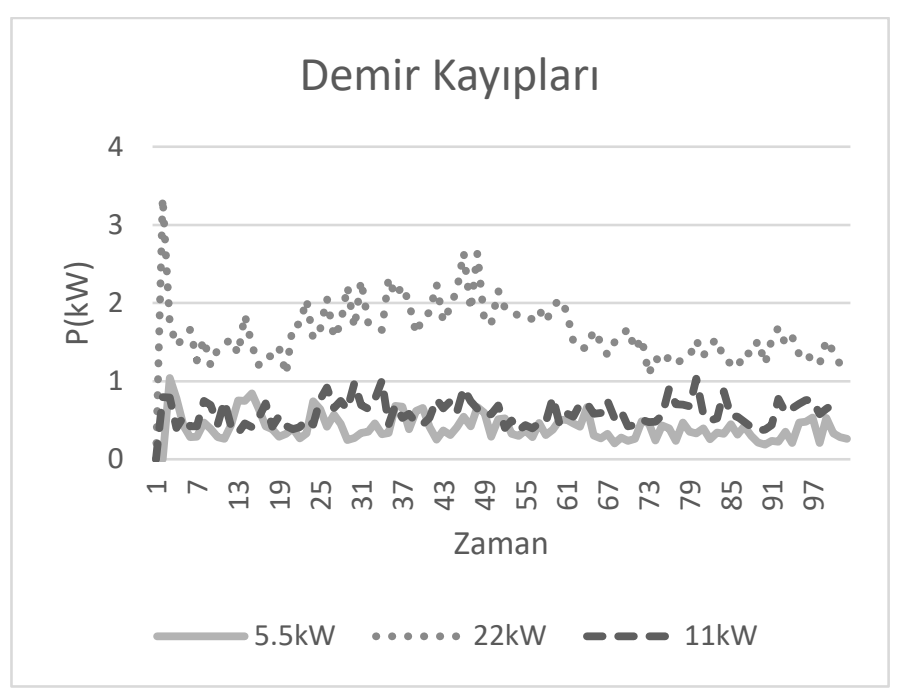

Şekil 5. Demir kayıplarl (Figure 5. Iron Losses)

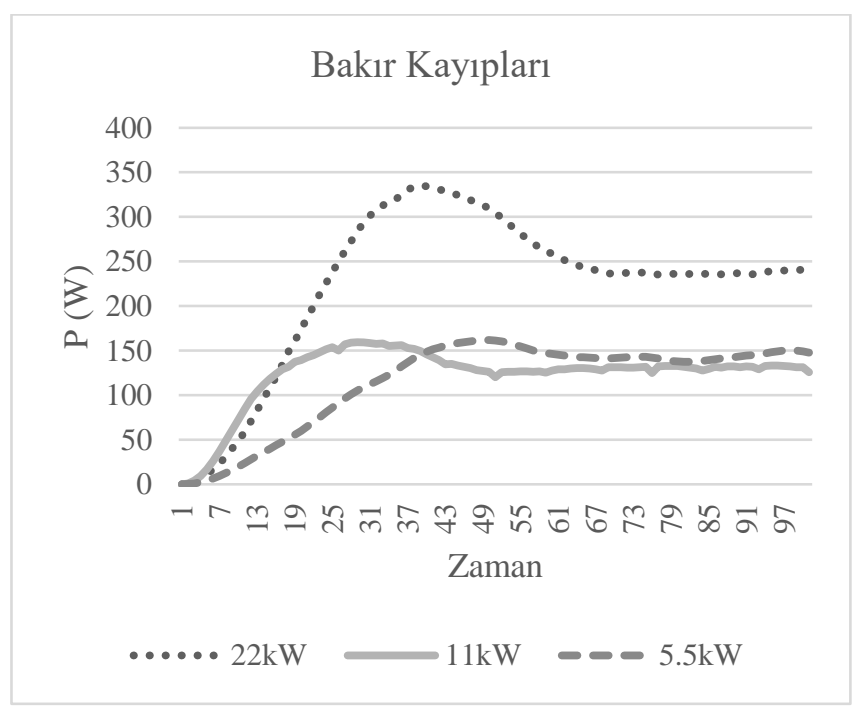

Şekil 6. Bakır kayıpları (Figure 6. Copper Losses)

\section{Araştırma Sonuçları ve Tartışma}

Bu bölümde analitik çözümler ve sonlu elemanlar analiziyle bulunan sonuçlar arasındaki sapmalar irdelenmiştir. Her üç generatör için de ağırlık hesaplamaları toplamlarında \%5'i geçmemiştir. Aynı şekilde verim hesaplamalarındaki sapma da $5.5 \mathrm{~kW}$ 'ta maksimum $\% 4.71$ olduğu görülmüştür. Fakat kayıp değerleri özellikle demir kayıplarında makul sınırların dışında kalmıştır. Sapmaların kaynakları araştırılarak analitik modelde kayıpların tayininde kullanılan katsayılar ile kesitlerin hesaplanmasında kullanılan denklemler irdelenerek güncellenmesi gerektiği anlaşılmıştır.

Çalışmanın son aşamasında elde edilen üç farklı generatörün nihai ağırlık-güç oranı ve verim karşılaştırılması yapılmıştır. Şekil 7'de yer alan sonuçlara göre $\mathrm{P} / \mathrm{W}$ oranında en yüksek değer $22 \mathrm{~kW}$ ' lık generatöre aitken verim açısından en başarılı $11 \mathrm{~kW}$ 'lık generatör olmuştur.

\begin{tabular}{|c|c|c|c|}
\hline \multicolumn{4}{|c|}{$22 \mathrm{~kW}$} \\
\hline & Analitik & Maxwell 3D & Sapma (\%) \\
\hline$m_{s c}$ & 12,33 & 13,13 & 6,11 \\
\hline$m_{r y}$ & 2,20 & 2,18 & 1,06 \\
\hline$m_{C u}$ & 6,45 & 5,33 & 20,95 \\
\hline$m_{m a g}$ & 0,64 & 0,65 & 1,60 \\
\hline$m_{\text {toplam }}$ & 21,63 & 21,30 & 1,53 \\
\hline$P_{c u}$ & 332,22 & 240,00 & 38,43 \\
\hline$P_{i r}$ & 753,32 & 1560,00 & 51,71 \\
\hline Toplam Kayıp & 1085,50 & 1800,00 & 39,69 \\
\hline Verim & 95,30 & 92,44 & 3,10 \\
\hline \multicolumn{4}{|c|}{$11 \mathrm{~kW}$} \\
\hline$m_{s c}$ & 5,66 & 5,54 & 2,14 \\
\hline$m_{r y}$ & 1,09 & 1,10 & 0,55 \\
\hline$m_{C u}$ & 5,23 & 5,22 & 0,23 \\
\hline$m_{m a g}$ & 0,39 & 0,39 & 0,85 \\
\hline$m_{\text {toplam }}$ & 12,38 & 12,25 & 1,04 \\
\hline$P_{c u}$ & 192,82 & 133,33 & 48,32 \\
\hline$P_{i r}$ & 329,51 & 598,80 & 44,97 \\
\hline Toplam Kayıp & 522,33 & 727,50 & 28,20 \\
\hline Verim & 95,47 & 93,79 & 1,79 \\
\hline \multicolumn{4}{|c|}{$5,5 \mathrm{~kW}$} \\
\hline$m_{s c}$ & 3,41 & 3,51 & 2,75 \\
\hline$m_{r y}$ & 0,57 & 0,54 & 5,96 \\
\hline$m_{C u}$ & 2,40 & 2,20 & 8,98 \\
\hline$m_{m a g}$ & 0,28 & 0,25 & 13,29 \\
\hline$m_{\text {toplam }}$ & 6,67 & 6,50 & 2,56 \\
\hline$P_{c u}$ & 105,74 & 143,85 & 26,50 \\
\hline$P_{i r}$ & 178,93 & 410,30 & 56,39 \\
\hline Toplam Kayıp & 284,66 & 554,15 & 48,63 \\
\hline Verim & 95,08 & 90,80 & 4,71 \\
\hline
\end{tabular}

Tablo 6. Analitik ve sonlu elemanlar çözümleri karşılaştırılması (Table 6. Comparison of analytical and finite element solutions)

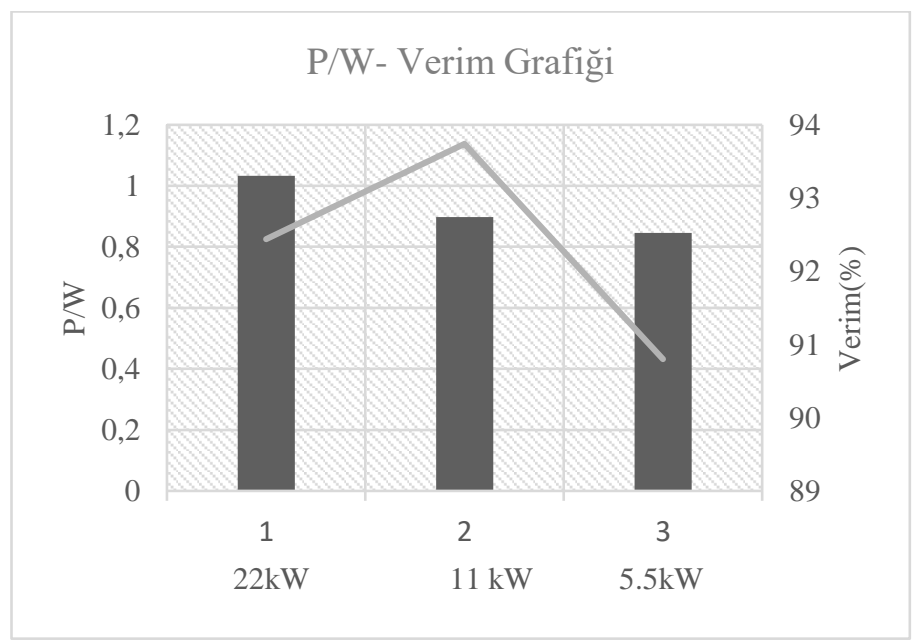

Şekil 7. $P / W$ ve verim karşılaştırması (Figure 7. P/W- efficiency comparison) 


\section{Sonuç}

Bu çalışmada yeni bir konsept olan havai rüzgâr enerji sistemleri için $44 \mathrm{~kW}$ gücün üç farklı güçteki generatör ile karşılanması durumunda oluşacak ağırlık-güç oranı ve verimler irdelenmiştir. Matlab ortamında optimize edilen analitik model sonucu üretilen tasarımlar sonlu elemanlar yöntemi kullanılarak Ansys Maxwell 3D yazılımı ile analiz edilmiştir. Sonuç olarak güç/ağırlık $(\mathrm{P} / \mathrm{W})$ oranları; $22 \mathrm{~kW}$ için $1.03 \mathrm{~kW} / \mathrm{kg} 11 \mathrm{~kW}$ için $0.89 \mathrm{~kW} / \mathrm{kg}$ ve $5.5 \mathrm{~kW}$ içinse $0.84 \mathrm{~kW} / \mathrm{kg}$, verim değerleri ise sırasıyla \%92,44, \%93,79, $\% 90$ olarak bulunmuştur. Generatörlerin hava aracına aerodinamik etkileri ve sistem güvenliği gibi parametreler ihmal edildiğinde yüksek güçlü generatörün verimli ve gücüne göre görece daha hafif olması sebebiyle tercih edilebilir olduğu sonucuna varılmıştır.

\section{Kaynakça}

Adhikari, J., \& Panda S. K. (2015). Generation and Transmission of Electrical Energy in High-Altitude Wind Power Generating System. IEEE Journal of Emerging and Selected Topics in Power Electronics, 3 (2). https://doi.org/10.1109/JESTPE.2015.2388702

Airborne Wind Europe. (2021, November 12). About Airborne Wind Energy. https://airbornewindeurope.org/aboutairborne-wind-energy/

Aull, M., Stough, A., \& Cohen K. (2020). Design Optimization and Sizing for Fly-Gen Airborne Wind Energy Systems. Automation, 1 (1),1-16. https://doi.org/10.3390/automation1010001

Bianchi, N., Bolognani, S., \& Frare P. (2006). Design criteria for high-efficiency SPM synchronous motors. IEEE Trans. Energy Conversion, $21 \quad$ (2), 396-404. https://doi.org/10.1109/TEC.2005.853720

Carlos, G. G., Bulmaro, M. G., Honorato, A. C., \& Amparo, P. M. (2010). Design of a 3.5 meters rotor two bladed horizontal axis wind turbine. Proc. 20th Int. Conf. on Electronics, Communications and Computer (CONIELECOMP 2010), 247-251. doi: 10.1109/CONIELECOMP.2010.5440758

Cherubini, A., Papini, A., Vertechy, R., \& Fontana, M. (2015). Airborne Wind Energy Systems: A review of the technologies. Renewable and Sustainable Energy Reviews, 51, pp. 1461-1476. https://doi.org/10.1016/j.rser.2015.07.053

Emetor. (2021, September 10). Electric motor winding calculator. https://www.emetor.com/windings/

Gammeter, C., Drapela, Y., Tüysüz A., \& Kolar J.W. (2015). Weight optimization of a machine for airborne wind turbines. IECON 2014- 40th Annual Conference of the IEEE Industrial Electronics https://doi.org/10.1109/IECON.2014.7048616

Society.

Kitekraft. (2021, November 12). https://www.kitekraft.de/

Loyd, M. L., (1980). Crosswind kite power. J. Energy, 4 (3), 106111.

Rancourt, D., Bolduc-Teasdale, F., Bouchard E.D., Anderson, M. J., \& Mavris, D. N. (2016). Design space exploration of gyrocopter-type airborne wind turbines. Wind Energy, 19 (5), 895-909. https://doi.org/ 10.1002/WE.1873.

Seo, U.-J., Chun, Y.-D., Choi, J.-H., Chung, S.-U., Han, P.-W., \&amp; Koo, D.-H. (2013). General characteristic of fractional slot double layer concentrated winding synchronous machine. Journal of Electrical Engineering and Technology, $8(2), \quad 282-287$. https://doi.org/10.5370/jeet.2013.8.2.282
Subotic, I., Gammeter, C., Tüysüz, A., \& Kolar J. W. (2016). Weight optimization of an axial-flux PM machine for airborne wind turbines. IEEE International Conference on Power Electronics, Drives and Energy Systems (PEDES). https://doi.org/10.1109/PEDES.2016.7914327

Tarımer, İ., Arslan, S., \& Güven, M. E. (2012). Investigation for Losses of M19 and Amorphous Core Materials Asynchronous Motor by Finite Elements Methods. Elektronika Ir Elektrotechnıka, 18 https://doi.org/10.5755/j01.eee.18.9.2797

Windlift. (2021, November 12). Airborne Power Generators. https://windlift.com/

Zhang, X., L1, L., \& Zhang, C. (2020). Mass Optimization Method of a Surface-Mounted Permanent Magnet Synchronous Motor Based on a Lightweight Structure. IEEE-Access, 8, 40431-

40444. https://doi.org/10.1109/ACCESS.2020.2974908

Zhu, Z. Q., Howe, D., Bolte, E, \& Ackermann B. (1993). Instantaneous magnetic field distribution in brushless permanent magnet DC motors. I. Open-circuit field. IEEE Trans. Magn., 29 (1), 124-135. https://doi.org/10.1109/20.195559 